\title{
Erratum to: Body condition is associated with adrenocortical response in the barn swallow (Hirundo rustica L.) during early stages of autumn migration
}

Sari Raja-aho $\cdot$ Petri Suorsa $\cdot$ Minna Vainio $\cdot$

Mikko Nikinmaa $\cdot$ Esa Lehikoinen $\cdot$ Tapio Eeva

Published online: 8 April 2010

(C) Springer-Verlag 2010

\section{Erratum to: Oecologia}

DOI 10.1007/s00442-009-1553-0

Unfortunately, Fig. 4 of the original article has been wrongly published without dates in the $x$ axis. The corrected version of Fig. 4 is given below:

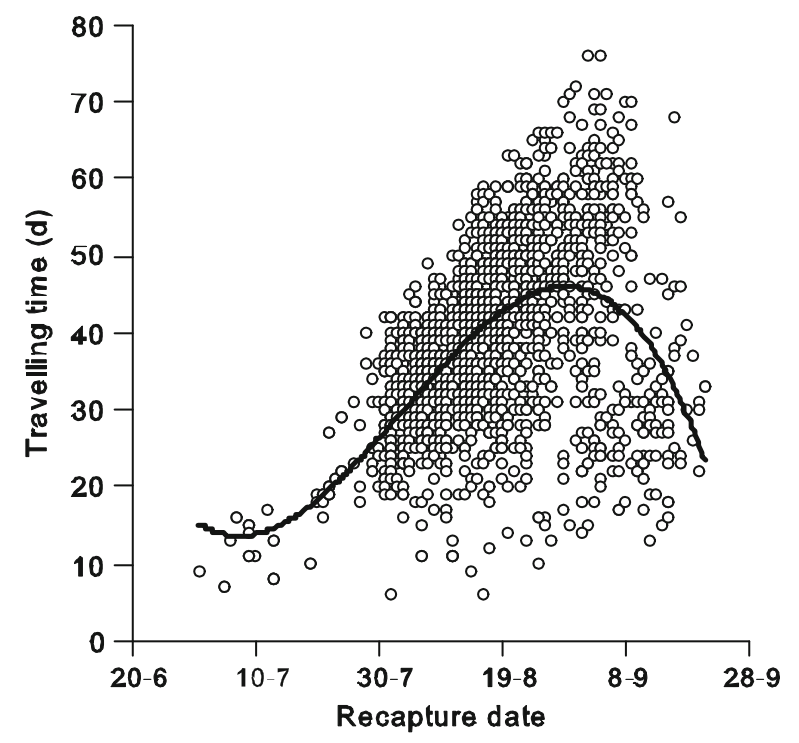

The online version of the original article can be found under doi:10.1007/s00442-009-1553-0.

S. Raja-aho $(\bowtie) \cdot$ P. Suorsa · E. Lehikoinen · T. Eeva Section of Ecology, Department of Biology,

University of Turku, 20014 Turku, Finland

e-mail: sari.raja-aho@turku.fi

M. Vainio $\cdot$ M. Nikinmaa

Laboratory of Animal Physiology, Department of Biology,

University of Turku, 20014 Turku, Finland 